\title{
Tiliroside: anti-liver cancer effects and investigation of aldose reductase inhibition properties with molecular modeling studies
}

\author{
Meng Sun, Haisong Wang, Meng Li, Jiangtao Bai
}

Interventional Vascular Surgery, Affiliated Hospital of Hebei University, Baoding, China

Submitted: 20 October 2021; Accepted: 26 October 2021

Online publication: 29 October 2021

Arch Med Sci

DOI: https://doi.org/10.5114/aoms/143350

Copyright @ 2021 Termedia \& Banach

\section{Abstract}

Introduction: Biotechnology is the field to yield modern systems, tools, and materials by taking control at the atomic and molecular levels using the features that appear on those surfaces. Applications for biotechnology in medical diagnostics, food, medicine, environment, energy, chemistry, physics, etc., introduce this technology in an interdisciplinary and cross-sectoral context. Tiliroside (kaempferol 3-0-(600-0-p-coumaroyl)-b-D glucopyranoside) is a glycosidic flavonoid found in several medicinal and dietary sources, such as linden, rose hips and strawberries. In recent years, plant extracts have been identified as a new way to discover new anti-diabetic drugs. Due to the unwanted side effects associated with current drugs, an increasing number of patients are demanding to use natural products with anti-diabetic activity.

Material and methods: In our study, the inhibition result of isoliquiritigenin on aldose reductase showed a lower $I C_{50}$ value $=0.98 \pm 0.15 \mathrm{ng} / \mathrm{ml}$. The biological activities of tiliroside against human aldose reductase were investigated using a molecular docking study.

Results and conclusions: The results of these calculations revealed the high affinity of this compound for the enzyme. This binding affinity could be considered as a reason for the low $\mathrm{IC}_{50}$ of tiliroside against the aldose reductase. In the oncological part of the recent study, the cells treated with tiliroside were assessed by MTT assay for $48 \mathrm{~h}$ regarding the cytotoxicity and anti-liver cancer properties in normal (HUVEC) and liver cancer cell lines, i.e. SNU387, LMH/2A, MCA-RH7777, and N1-S1 Fudr.

Key words: tiliroside, liver cancer interventional therapy, aldose reductase, enzyme inhibition, molecular docking studies.

\section{Introduction}

Dietary flavonoids are a large group among the polyphenols, including approximately 8000 compounds and frequently occurring in vegetables, fruits, chocolate, and beverages such as coffee, red wine, and tea $[1,2]$. Their role is mostly connected with biological activity; they tend to show antiallergic, hepatoprotective, antioxidant, anti-inflammatory, antiviral, antithrombotic, and anticarcinogenic potential. Many of these activities can be explained by antioxidant mechanisms, including inhibition of enzyme activities in the formation of reactive oxygen species

\author{
Corresponding author: \\ Dr. Jiangtao Bai \\ Interventional Vascular \\ Surgery \\ Affiliated Hospital \\ of Hebei University \\ 212 Yuhua East Road \\ Baoding 071000 \\ China \\ E-mail: bjt0321@126.com
}


<smiles>O=C(/C=C/c1ccc(O)cc1)OC[C@H]1O[C@@H](Oc2c(-c3ccc(O)cc3)oc3cc(O)cc(O)c3c2=O)[C@H](O)[C@@H](O)[C@@H]1O</smiles>

Figure 1. Chemical structure of tiliroside

(ROS) or chelation of microelements such as iron or copper that could presumably enhance ROS generation [3]. Among the flavonoid derivatives is tiliroside (Figure 1), also named kaempferol 3-O-glucoside-6"-E-coumaroyl or [(2R,3S,4S,5R,6S)-6-[5,7dihydroxy-2-(4-hydroxyphenyl)-4-oxo-chromen-3yl]oxy-3,4,5-trihydroxyoxan-2-yl]methyl (E)-3-(4hydroxyphenyl)-prop-2-enoate [4]. It is a flavonoid contained in several plants used as human food. Plant materials such as fruits, leaves, and roots containing tiliroside are widely used as both food and medicines and are employed in the treatment of various ailments, such as Rubus chingii, which is part of the traditional Chinese tonic Fu Pen $\mathrm{Zi}$ and other medicines used to treat wounds, diarrhea, inflammatory disorders and diabetes. As has been proven, tiliroside exerts effects such as antioxidant, antiobesity, antidiabetic, and others, with no reports of its toxicity against noncancer cells, and at the same time even increasing the viability of hepatocarcinoma HepG2 cells [5, 6].

Aldose reductase (alditol: $\mathrm{NADP}^{+}$oxidoreductase, EC 1.1.1.21, ALR2) is a member of the aldo-keto aldose superfamily and is the first enzyme of the polyol pathway. X-ray crystallography studies performed with porcine and human aldose reductases revealed that the enzyme is in the form of a barrel made up of $\alpha / \beta$ folds and that the folds of its coenzyme NADPH are attached to the C-terminal end $[7,8]$. While the aldose reductase enzyme reduces D-glucose to D-sorbitol, it uses NADPH as a coenzyme. D-sorbitol formed as a result of this reaction is transformed into $D$-fructose by the catalysis of sorbitol dehydrogenase. In the case of hyperglycemia, a large increase in AR enzyme activity occurs, with the effect of glucose metabolism increasing 2-4 times [9]. Aldose reductase is a member of the aldo-keto superfamily (AKR), most members of which are responsible for the reduction of substrates such as aliphatic and aromatic aldehydes, monosaccharides, steroids, polycyclic aromatic hydrocarbons and isoflavanoids, and are also involved in detoxification steps. The human aldose reductase enzyme consists of 316 amino acids and is a protein with a molecular mass of $36 \mathrm{kDa}$. Thus, AR inhibitors
(ARIs) are being investigated in a fairly wide range as therapeutic agents for delaying the progression or preventing the onset of diabetic complications $[10,11]$.

Theoretical studies are essential methods, which should be added to the experimental investigations. These approaches could support the reliability of experimental studies and provide beneficial insight into the interactions and related mechanisms [12]. One of the most popular approaches in this area is molecular docking, which determines the interactions between various ligands and biomolecules. These data could confirm the outcomes of laboratory investigations. The most probable mechanism in which the ligand can interact with the enzyme is predictable using molecular docking studies [13].

In the recent research, we also investigated tiliroside in the cytotoxicity and anti-liver cancer studies against SNU-387, LMH/2A, MCA-RH7777, and N1-S1 Fudr cell lines.

\section{Material and methods}

\section{Enzyme study}

Solutions used: 1) $0.8 \mathrm{M} \mathrm{Na-phosphate} \mathrm{buffer,}$ $\mathrm{pH}=5.5,2) 0.11 \mathrm{mM}$ NADPH solution $3.7 \mathrm{mM}$ DL-glyceraldehyde solution. Measuring the activity of the AR enzyme: a modification of the procedure used by Cerelli et al. was applied [14]. The reaction medium was prepared by adding $0.1 \mathrm{ml}$ of isolated enzyme to $0.25 \mathrm{~mL}$ of $\mathrm{Na}$-phosphate buffer, $0.1 \mathrm{ml}$ of NADPH, and $0.45 \mathrm{ml}$ of distilled water, to a volume of $1 \mathrm{ml}$. The reaction was initiated by adding $0.1 \mathrm{ml}$ of DL glyceraldehyde to the cuvette prepared above [15]. Using the spectrophotometer, the decrease in NADPH concentration at $340 \mathrm{~nm}$ and room temperature was followed for 3 min. Later, the intervals with linear absorbance values were determined and slope calculations were made. The slope values were calculated by applying the formula below to calculate the activity of the enzyme in $U / I$ [16]. For the $I C_{50}$ study, we used six different inhibitor concentrations and wrote down the activities and then plotted the $I C_{50}$. After obtaining the (concentration-percent activity) equation, we calculated the $I_{50}$ value. We repeated this task 3 times and calculated the standard deviation and found that our work was correct [17].

\section{Molecular docking study}

The chemical and biological activities of compounds could be easily determined using theoretical studies. One of the common methods for this object is molecular docking investigation. The enzyme utilized in this work was human aldose reductase (PDB ID: 1US0) [18]. The biological ac- 
tivities of tiliroside were investigated against this enzyme. The structure of the enzyme was obtained from the Protein Data Bank (http://www.rcsb.org/ pdb) and prepared with the protein preparation module of the Schrödinger Suite [19]. The addition of hydrogen atoms, removal of the water molecules, and optimization of the structure were performed using this module. The energy was then minimized utilizing optimized potentials for liquid simulations (OPLS3e) force field. The active sites of the structure were predicted using the SiteMap module of Schrödinger [20]. The structure of tiliroside in the SDF format was downloaded from the PubChem database and prepared with the LigPrep module of Schrödinger [21]. Lastly, molecular docking was performed using Glide from the Schrödinger suite.

\section{Anti-liver cancer properties of tiliroside}

The process of the controlled culture of prokaryotic or eukaryotic cells in a filtered or unfiltered flask or cell culture plate by a suitable culture medium is called. This term is mostly used for culturing multicellular cells. Special culture media are used to culture cells. The cells are usually cultured at $37^{\circ} \mathrm{C}$ in equipment such as $\mathrm{CO}_{2}$ incubators. Cell culture should be performed under aseptic (disinfected) conditions because the growth of these cells is much slower than the growth of bacteria and yeasts and there is a possibility of contamination of the culture medium. Antibiotics such as penicillin, streptomycin, or gentamicin are sometimes used to stop the growth of bacteria. In order for cells to proliferate well in culture medium, their density in culture medium must be low. For this purpose, the cells should be passed to fresh culture medium from time to time. One of the goals of cell culture is to study cells in terms of how they grow, their nutritional needs, and the reasons they stop growing, each of which can have a profound effect on the morphology of the cells we see under a microscope. Therefore, to study the cell growth cycle, develop methods to control the growth of cancer cells and modulate the expression of genes, it is necessary to cultivate these cells in an external environment [22]. With the help of cell culture, cells that are in different stages of differentiation and can be differentiated into other cells with the help of hormones and growth factors can be prepared. With the help of cell culture, homogeneous cells can be prepared and intracellular activities such as DNA replication, DNA transcription synthesis, RNA and protein synthesis and other details related to metabolism can be studied. It is also possible to examine the subsequent events and intracellular currents, such as the displacement of these complexes, the type of intracellular messages, and how the mes- sages are transmitted, after connecting different molecules to the corresponding membrane receptor. The cultured cells can be stored frozen at very low temperatures. Such conditions will maintain the growth rate or genetic composition of these cells and they can be thawed and used again at the appropriate time. This prevents aging of cells, while it is currently not possible to prevent the aging of animals. When working with laboratory animals, systemic changes due to the effect of the animal's natural homeostasis or the stress of the experiments on the results should be considered. While the use of cell culture eliminates this problem. In addition, standardizing laboratory tests is easier and more practical than tests on living organisms. In laboratory environments, it is much easier to control the physical and chemical factors in the living environment of cells, including acidity, heat, osmotic pressure, and the pressure of gases such as oxygen and carbon dioxide. Cells that are taken directly from the individual are known as primer cells and have a limited lifespan. Most cells have a limited lifespan, except for those taken from a tumor. An immortal cell line can proliferate indefinitely by creating a random or targeted mutation (such as artificial gene expression) and be established as a representative of specific cell types [22].

The cytotoxic effects of synthesized tiliroside on SNU-387, LMH/2A, MCA-RH7777, and N1-S1 Fudr cell lines were assessed using the MTT colorimetric method.

In the recent study, the cells were cultured in medium (RPMI1640 = Roswell Park Memorial Institute 1640 ) with $10 \%$ FBS combined with penicillin and streptomycin antibiotics in an incubator containing $5 \% \mathrm{CO}_{2}$ in a flask (T25). After three passages for purification, the cells were used to perform the next steps. Cell count and the number of viable cells were performed with a hemocytometer slide using trypan blue. Evaluation of the cytotoxic effect of the tiliroside was performed by the modified 3-(4,5-dimethylthiazol-2-yl)-2,5-diphenyl-2H-tetrazolium bromide (MTT) colorimetric test. In this method, MTT, which is yellow, is converted to insoluble and formazan purple dye by the dehydrogenase enzymes in the mitochondria of active cells. The adsorption of this compound can be measured after dissolving at 570-540 nm. After two days and covering the flask bottom with cells, the cell layer adhering to the flask bottom was isolated enzymatically using trypsin-EDTA (5\%) (tetraacetic acid ethylenediamine); after transfer to sterile test tubes, it was centrifuged at $2000 \mathrm{rpm}$ for $10 \mathrm{~min}$. The cells were then resuspended in a fresh culture medium with the help of a Pasteur pipette and cell suspension $\left(10^{6} \mathrm{ml} / \mu \mathrm{g}\right)$ was prepared from them. $40 \mu \mathrm{l}$ of this 
cell suspension (equivalent to $10^{4} \times 4$ cells) was poured into 96-well plate flat-bottomed wells (for cell culture). Then the final volume of each well with $10 \%$ FBS medium reached $200 \mu \mathrm{l}$. The first row containing cell suspension was considered as a negative control (control). After incubation for 18-24 $\mathrm{h}$ to remove cells from the stress caused by trypsinization, the supernatant was removed slowly and carefully. A new medium was added to all rows with different concentrations of the tiliroside (only a new medium was added to the negative and positive control rows), so that the diluted tiliroside with concentrations of $1-1000 \mu \mathrm{g} / \mathrm{ml}$ was added to the third to sixth rows, respectively; the plate was incubated in $\mathrm{CO}_{2}$ for 48,24 and $72 \mathrm{~h}$. After the incubation time, the plate was taken out of the incubator and $20 \mu \mathrm{l}$ of MTT (Sigma) was added to all wells, and incubated for $3 \mathrm{~h}$. The supernatant was then gently removed and $100 \mu \mathrm{l}$ of DMSO was added to the wells and pipetted to dissolve the formazan crystals. The amount of light absorption (OD) according to the intensity of the blue color of formazan at $540 \mathrm{~nm}$ was read by an ELISA reader. To convert OD to the percentage of living cells, the following formula was used and the percentage cell viability at each concentration was calculated after 48, 24 and 72 h [22]: cell viability $(\%)=($ sample $\mathrm{A} /$ Control $\mathrm{A}) \times 100$.

The concentration of the tested compounds that reduced the percentage cell viability by half was considered as the $\mathrm{IC}_{50}$ (half maximal inhibitory concentration) [22].

\section{Statistical analysis}

At least three independent replications were performed for each datum and the result was presented as mean \pm SD. Data statistical analysis was done with SPSS software version 22 and one-way ANOVA and Duncan tests. Significance was considered at the level of $p \leq 0.05$.

\section{Results and discussion}

\section{Enzyme results}

This compound showing inhibitory effects was determined by measuring activity at different inhibitor concentrations related to inhibition studies. Also, for this compound, \% activity [I] graphs were drawn for those with high inhibitory effects, and $I C_{50}$ values were calculated from the equation of the curve $[23,24]$. The AR enzyme has a relationship with many metabolic pathways other than the polyol pathway. These include cardiovascular diseases, inflammation, depression, renal failure, ovarian anomalies and cancer [25]. These regulatory effects of the $A R$ enzyme increase the importance of inhibition studies on this enzyme. For example, AR inhibitors are also used in the treatment of many diseases such as colon cancer and rheumatoid arthritis. In our study, the inhibitory effect of isoliquiritigenin on aldose reductase showed a lower IC $\mathrm{C}_{50}$ value $=0.98 \pm 0.15 \mathrm{ng} / \mathrm{ml}$ [26]. It has been reported that the aldose reductase enzyme is overexpressed in many cancer cells. One of the typical features of colon cancer is the overexpression of the iCOX-2 enzyme. The iCOX-2 enzyme performs the synthesis of prostaglandins from arachidonic acid, which enable colonic epithelial cells to proliferate in an uncontrolled manner. In colon epithelial cells, the transcriptional regulation of COX-2 is provided by various growth factors (TGF, IGF, VEGF, FGF) and cytokines (TNF- $\alpha$ ) [27]. However, growth factors and cytokines activate the transcription of the aldose reductase enzyme. Cytokines such as TNF- $\alpha$ also increase the risk of developing colon cancer. Aldose reductase inhibition prevents the activation of TNF- $\alpha$-induced PKC and NF- $\kappa$ B, so the COX-2 enzyme cannot be expressed. This shows that the AR enzyme is necessary for the activation of NF- $\mathrm{B}$ [28].

\section{Molecular docking results}

Molecular docking investigation is the theoretical method that was applied for the prediction of biological activities of tiliroside. The docking pose of tiliroside is presented in Figures 2 and 3 shows the interactions of tiliroside with aldose reductase. The docking results indicate that the ligand has created four hydrogen bonds with various residues of the enzyme. The ligplot of the interactions shows that these residues are Trp20, Trp111, lle260, and Lys262. As it is vividly clarified, the $\mathrm{O}_{13}$ atom of tiliroside is very active since it has created two hydrogen bonds with Ile260 and Lys 262. Some of the obtained parameters determined through the calculations are presented in Table I. The docking score is one of the parameters among various parameters obtained from the calculations [29], which shows the binding affinity between the ligands and enzyme. The efficiency of the ligand is numerically calculated with Glide Ligand Efficiency, which is an essential parameter. Glide Evdw and Glide Ecoul are interaction related parameters. The other parameter is Glide energy, which indicates the interaction energy, and the value of the interaction pose is calculated numerically and presented with Glide Emodel [30]. A large docking score shows the remarkable binding affinity of tiliroside to the enzyme. The other essential thing is the number of hydrophobic contacts, which is 13 . This large number of hydrophobic contacts and hydrogen bonds has provided strong interactions, which have led to a very low $\mathrm{IC}_{50}$ of $0.98 \mathrm{nM}$.

Cancer is recognized as one of the leading causes of death in today's society, and several 


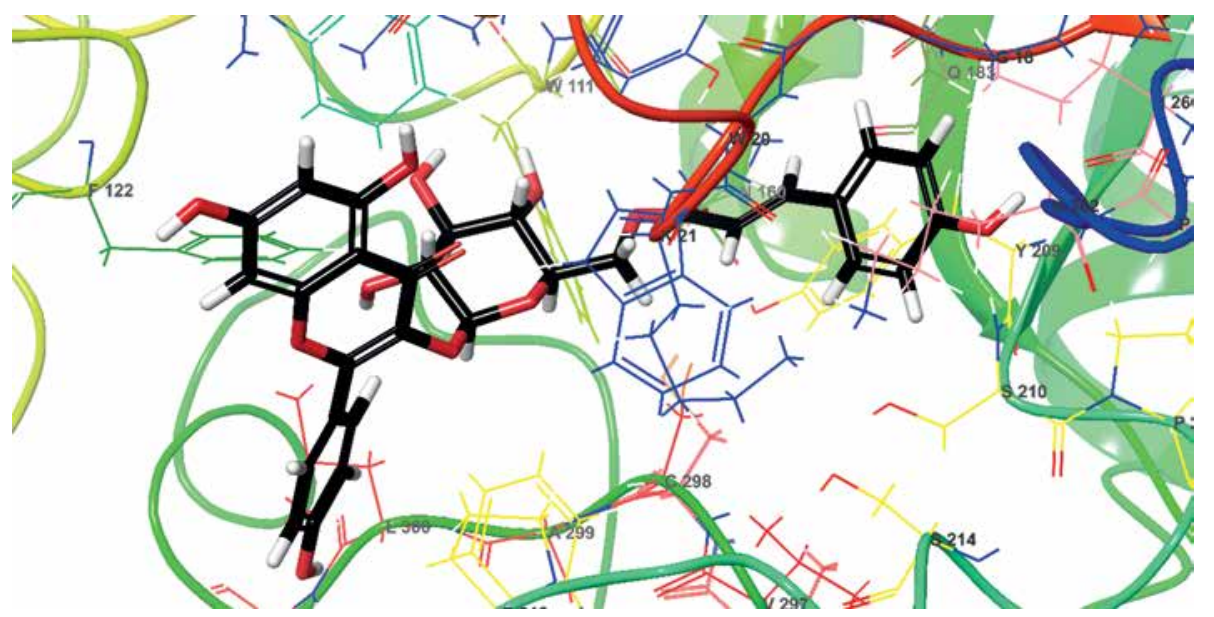

Figure 2. The docking pose of tiliroside among aldose reductase residues

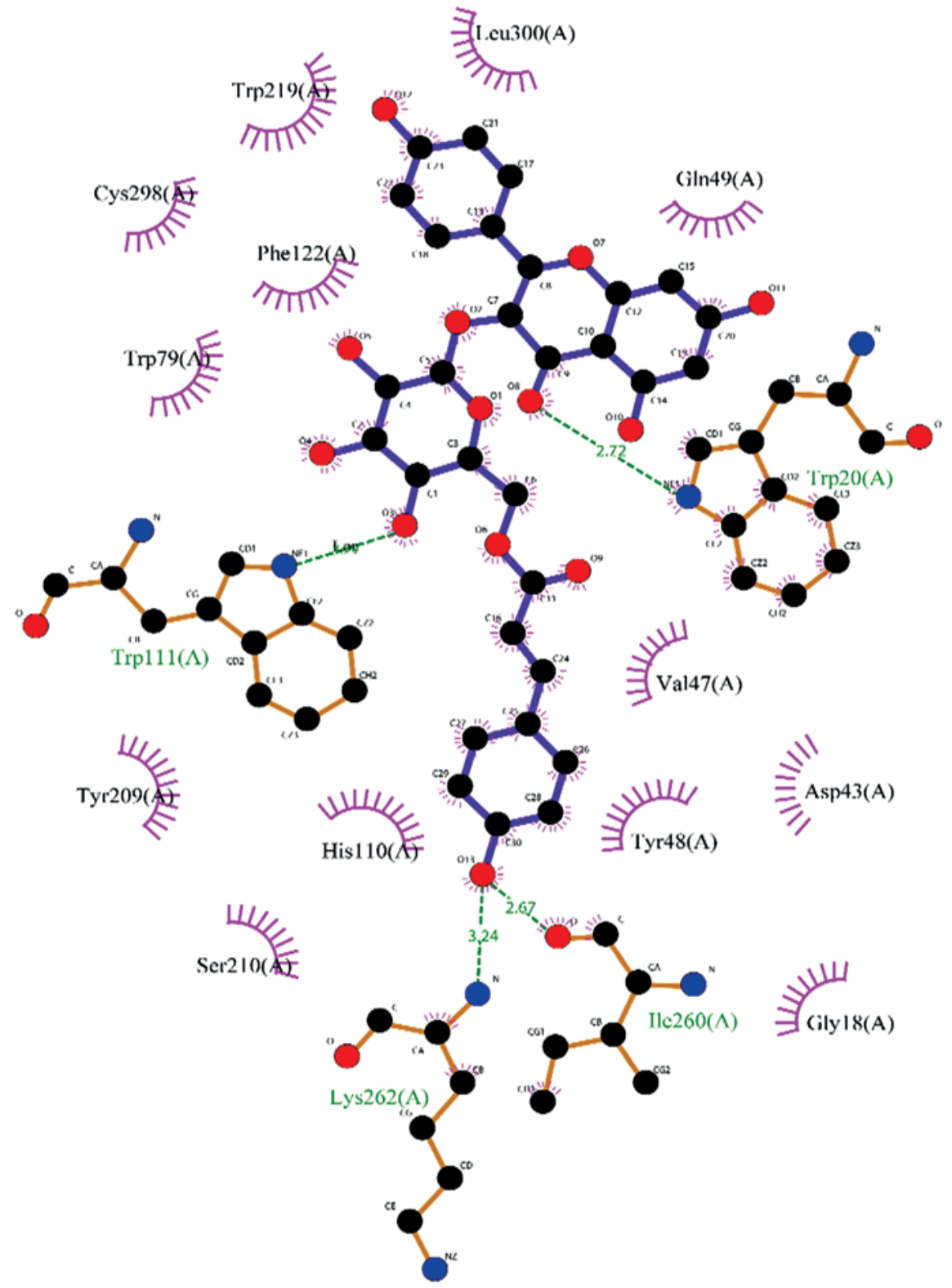

Figure 3. The interactions of tiliroside and aldose reductase. Green dashed lines indicate the hydrogen bonds, and semicircles show the hydrophobic contacts 
Table I. Parameters obtained from the molecular docking calculations

\begin{tabular}{|lc|}
\hline Parameter & Value \\
\hline $\mathrm{IC}_{50}[\mathrm{nM}]$ & 0.98 \\
\hline Docking score $[\mathrm{kcal} / \mathrm{mol}]$ & -10.425 \\
\hline Glide ligand efficiency $[\mathrm{kcal} / \mathrm{mol}]$ & -0.242 \\
\hline Glide Ecoul $[\mathrm{kcal} / \mathrm{mol}]$ & -17.557 \\
\hline Glide Evdw $[\mathrm{kcal} / \mathrm{mol}]$ & -36.283 \\
\hline Glide Emodel $[\mathrm{kcal} / \mathrm{mol}]$ & -86.882 \\
\hline Glide energy $[\mathrm{kcal} / \mathrm{mol}]$ & -53.840 \\
\hline
\end{tabular}

Table II. $I C_{50}$ of tiliroside in the anti-liver cancer experiment.

\begin{tabular}{|lc|}
\hline Variable & Tiliroside $[\mu \mathrm{g} / \mathrm{ml}]$ \\
\hline$I C_{50}$ against HUVEC & - \\
\hline$I C_{50}$ against SNU-387 & $464 \pm 0$ \\
\hline$I C_{50}$ against LMH/2A & $510 \pm 0$ \\
\hline$I C_{50}$ against MCA-RH7777 & $422 \pm 0$ \\
\hline$I C_{50}$ against $N 1-S 1$ Fudr & $414 \pm 0$ \\
\hline
\end{tabular}

drugs have been introduced to treat this disease, but most common cancers are not yet controllable and this disease imposes huge costs on the patient and society. The main factor in the development and progression of cancer has not yet been precisely identified; however, the available data suggest that metabolic disorders in the tissue and immune disorders may be involved in the development and exacerbation of this disease [22]. In addition, metabolic disorders in the production and excretion of oxygen free radicals are important factors affecting cancer cells. Free radicals are destructive compounds that are produced as a by-product by the body's chemical reactions and are destroyed by the body's defense system and enzyme system and antioxidants. However, in cases where the body's metabolic disorders and the production of free radicals are high and they are not destroyed by the neutralizing system, due to their instability, these compounds have a strong tendency to react with a variety of molecules in the body [22]. It is estimated that each cell in the human body is exposed to free radicals 10,000 times a day and DNA strands 5,000 times a day. Damage to cell components includes proteins (genetic disorder), fats (lipid oxidation), and cell membranes (permeability disorder); if the damage is not repaired, it leads to disruption of the chemical reaction and normal proteinization of the cell and the formation of harmful compounds and sometimes cancer cells in the body [22]. It is reported that thousands of cancer cells are produced daily in the human body and are killed by the body's defense system. In some cases, due to dysfunction of the above systems, cancer cells proliferate and conditions for cancer develop in different tissues. According to the above, antioxidants play a vital role in preventing disorders caused by the effects of free radicals and thus the prevention and treatment of cancer. Antioxidants are a wide range of molecular compounds with complex properties that combine with and neutralize free radicals. More than 60,000 types of molecular antioxidants have been identified so

B

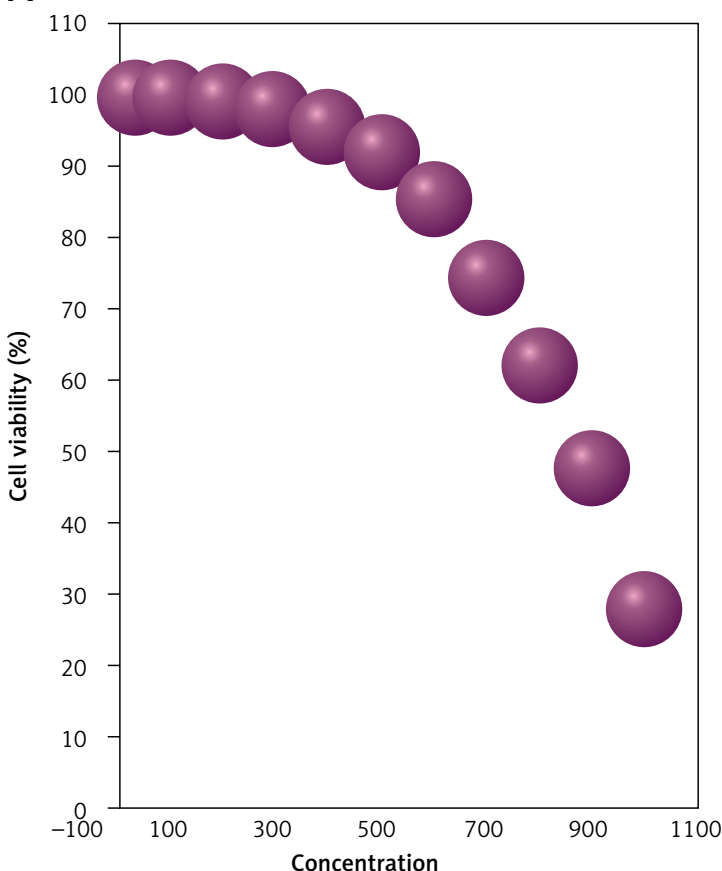

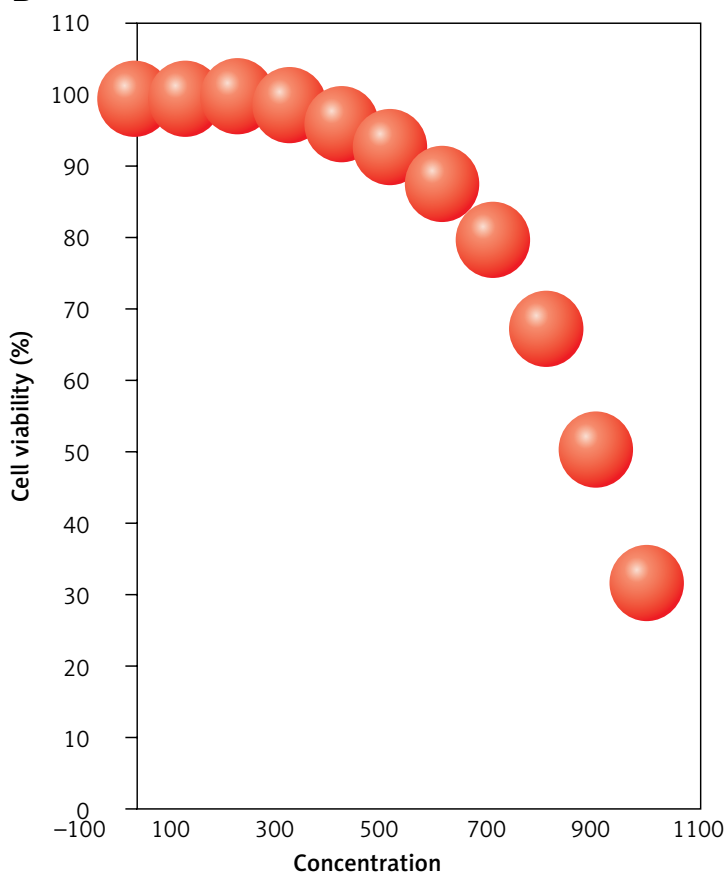

Figure 4. Anti-liver cancer properties (cell viability (\%)) of tiliroside: A - SNU-387, B - LMH/2A 
A

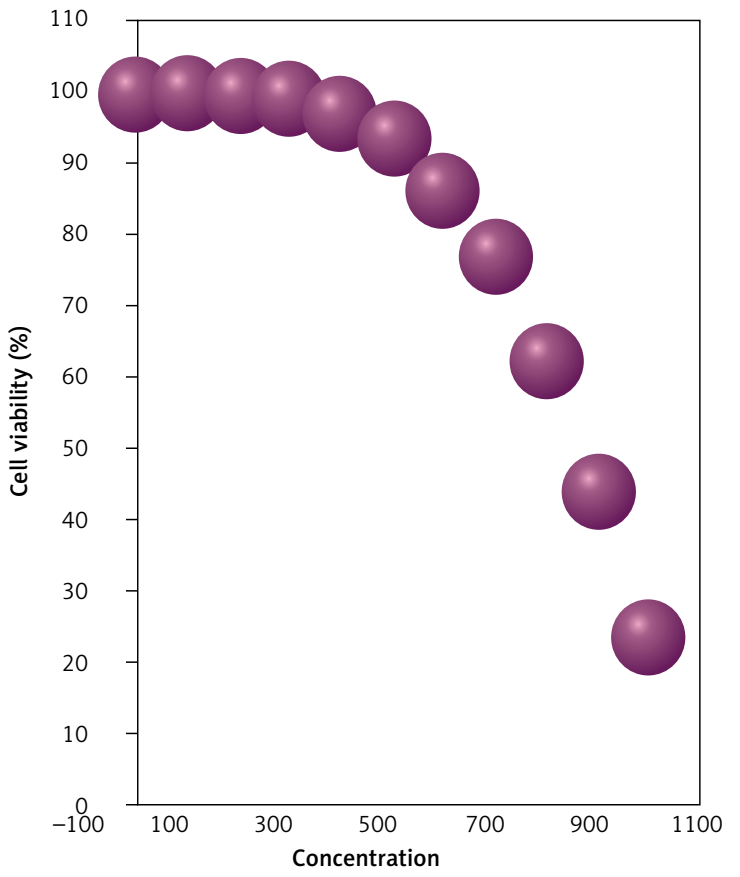

B

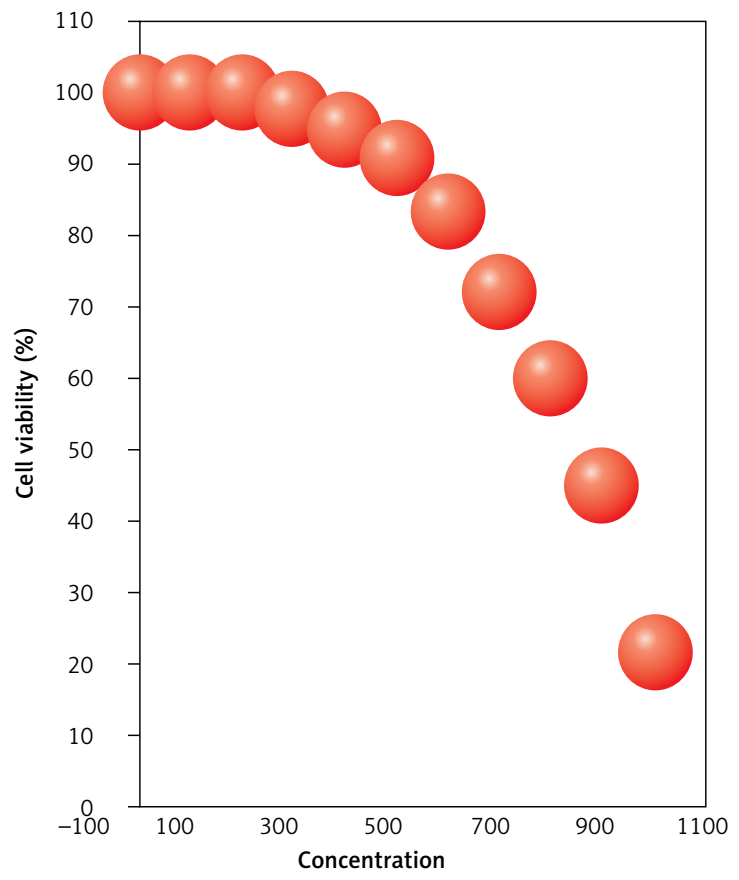

Figure 5. Anti-liver cancer properties (cell viability (\%)) of tiliroside: A - McA-RH7777, B - N1-S1 Fudr

far. Antioxidants can be effective in three known ways to prevent and treat cancer: 1 ) destruction of free radicals; 2 ) strengthening the immune system to destroy cancer cells; 3) preventing the adhesion of cancer cells to other cells and preventing their proliferation [22].

In this experiment, the cells treated with different concentrations of the present tiliroside were assessed by MTT assay for $48 \mathrm{~h}$ regarding the cytotoxic properties on normal (HUVEC) and liver cancer cell lines, i.e. SNU-387, LMH/2A, McARH7777, and N1-S1 Fudr (Table I; Figures 1-3).

The absorbance rate was evaluated at $570 \mathrm{~nm}$, which represented viability on the normal cell line (HUVEC) even up to $1000 \mu \mathrm{g} / \mathrm{ml}$ for tiliroside (Table II and Figures 4-6).

The viability of liver cancer cell lines (SNU-387, LMH/2A, MCA-RH7777, and N1-S1 Fudr) decreased dose-dependently in the presence of tiliroside.

The $I C_{50}$ values of tiliroside were 464, 510, 422, and $414 \mu \mathrm{g} / \mathrm{ml}$ against SNU-387, LMH/2A, MCARH7777, and N1-S1 Fudr cell lines, respectively (Table II and Figures 4-6).

In conclusion, the theoretical study of biological activities can give helpful knowledge, which can provide adequate insight into the mechanisms of experimental results. The molecular docking study is among the best methods, which provides the opportunity to evaluate the biological activities. The results of the molecular docking study revealed the high binding affinity of tiliroside to aldose reductase and elucidated the reason for the low $I C_{50}$ of this compound. The viability of liver

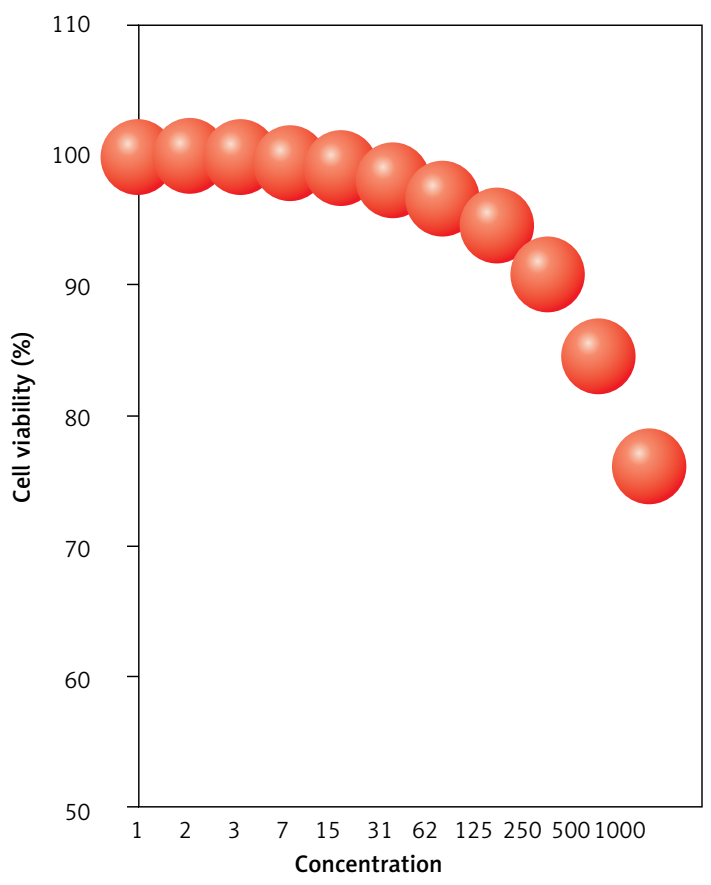

Figure 6. Cytotoxic effects of tiliroside against normal (HUVEC) cell line

cancer cell lines decreased dose-dependently in the presence of tiliroside. The $\mathrm{IC}_{50}$ values of tiliroside were $464,510,422$, and $414 \mu \mathrm{g} / \mathrm{ml}$ against SNU-387, LMH/2A, MCA-RH7777, and N1-S1 Fudr cell lines, respectively. After clinical study, tiliroside can be utilized as an efficient drug in the treatment of liver cancer in humans. 


\section{Conflict of interest}

The authors declare no conflict of interest.

\section{References}

1. Youdim KA, Qaiser MZ, Begley DJ, Rice-Evans CA, Abbott NJ. Flavonoid permeability across an in situ model of the blood-brain barrier. Free Rad Biol Med 2004; 36: 592-604.

2. Rimm ER, Katan MB, Ascherio A, Stampfer M, Willet W. Relation between intake of flavonoids and risk for coronary heart disease in male health professionals. Ann Intern Med 1996; 125: 384-9.

3. Wittemer SM, Ploch M, Windeck T, et al. Bioavailability and pharmacokinetics of caffeoylquinic acids and flavonoids after oral administration of artichoke leaf extracts in humans. Phytomedicine 2005; 12: 28-38.

4. Bajaj R, Chang CJ, McLaughlin JL, Powell RG, Smith CR. Tiliroside from the seeds of Eremocarpus setigerus. J Natural Products 1986; 49: 1174-5.

5. Calzada F, Basurto JC, Barbosa E, et al. Antiprotozoal activities of tiliroside and other compounds from Sphaeralcea angustifolia (Cav.) G. Don. Pharmacognosy Res 2017; 9: 133-7.

6. Cornelio VE, Maluf FV, Fernandes JB, et al. Isolation of tiliroside from Spiranthera odoratissima as inhibitor of Trypanosoma cruzi glyceraldehyde-3-phosphate dehydrogenase by using bioactivity-guided fractionation. J Brazil Chem Soc 2017; 28: 512-9.

7. Yawadio R, Tanimori S, Morita N. Identification of phenolic compounds isolated from pigmented rice and their aldose reductase inhibitory activities. Food Chemistry 2007; 101: 1616-25.

8. Chethan S, Dharmesh SM, Malleshi NG. Inhibition of aldose reductase from cataracted eye lenses by finger millet (Eleusine coracana) polyphenols. Biororg Med Chem 2008; 16: 10085-90.

9. Alim Z, Kilin N, Şengül B, Beydemir Ş. Inhibition behaviors of some phenolic acids on rat kidney aldose reductase enzyme; in vitro study. J Enzyme Inhib Med Chem 2017; 32: 277-84.

10. Saraswat M, Muthenna P, Suryanarayana P, Petrash JM Reddy GB. Dietary sources of aldose reductase inhibitors: prospects for alleviating diabetic complications. Asia Pac J Clin Nutr 2008; 17: 558-65.

11. Puppala M, Ponder J, Suryanarayana P, Reddy GB, Petrash $M$, Labarbera $D V$. The isolation and characcterisation of $\beta$-glucogallin as a novel aldose reductase inhibitor form Emblica Officinalis. PLoS One 2012; 4: e31399.

12. Koçyiğit ÜM, Taslimi P, Tüzün B, Yakan $H$, Muğlu $H$, Güzel E. "1,2,3-Triazole substituted phthalocyanine metal complexes as potential inhibitors for anticholinesterase and antidiabetic enzymes with molecular docking studies. J Biomol Struct Dyn 2020. doi: 10.1080/07391102.2020.1857842.

13. Jhong CH, Riyaphan J, Lin SH, Chia YC, Weng CF. Screening alpha-glucosidase and alpha-amylase inhibitors from natural compounds by molecular docking in silico. BioFactors 2015; 41: 242-51.

14. Cerelli KJ, Curtis DL, Dunn PH, Nelson PH, Peak TM, Waterbury LD. Antiinflammatory and aldose reductase inhibitory activity of some tricyclic arylacetic acids. J Med Chem 1986; 29: 2347-51.

15. Tomlinson DR, Stevens EJ, Diemel LT. Aldose reductase inhibitors and their potential for the treatment of diabetic complications. Trends Pharmacol Sci 1994; 15: 293-7.

16. Ramana KV, Willis MS, White MD, et al. Endotoxin-in- duced cardiomyopathy and systemic inflammation in mice is prevented by aldose reductase inhibition. Circulation 2006; 114: 1838-46.

17. Hotta N, Toyota T, Matsuoka K, et al. Clinical efficacy of fidarestat, a novel aldose reductase inhibitor, for diabetic peripheral neuropathy: a 52-week multicenter placebo-controlled double-blind parallel group study. Diabetes Care 2001; 24: 1776-82.

18. Howard El, Sanishvili R, Cachau RE, et al. Ultrahigh resolution drug design I: details of interactions in human aldose reductase-inhibitor complex at $0.66 \AA$. Proteins 2004; 55: 792-804.

19. Schrödinger Release 2020-4: Protein Preparation Wizard; Epik, Schrödinger, LLC, New York, NY 2016; Impact, Schrödinger, LLC, New York, NY 2016; Prime, Schrödinger, LLC, New York, NY 2020.

20. Poustforoosh A, Hashemipour H, Tüzün B, Pardakhty A, Mehrabani M, Nematollahi MH. Evaluation of potential anti-RNA-dependent RNA polymerase (RdRP) drugs against the newly emerged model of COVID-19 RdRP using computational methods. Biophys Chem 2021; 272: 106564.

21. Schrödinger Release 2020-4: LigPrep, Schrödinger, LLC, New York, NY 2020.

22. Lu Y, Wan X, Li L, Sun P, Liu G. Synthesis of a reusable composite of graphene and silver nanoparticles for catalytic reduction of 4- nitrophenol and performance as anti-colorectal carcinoma. J Materials Res Technol 2021; 12: 1832-43.

23. Ramana KV, Bhatnagar A, Srivastava SK. Aldose reductase regulates TNF-alpha-induced cell signaling and apoptosis in vascular endothelial cells. FEBS Lett 2004; 570: 189-94.

24. Saxena A, Tammali R, Ramana KV, Srivastava SK. Aldose reductase inhibition prevents colon cancer growth by restoring phosphatase and tensin homolog through modulation of miR-21 and FOXO3a. Antioxid Redox Signal 2013; 18: 1249-62.

25. Tammali R, Reddy AB, Srivastava SK, Ramana KV. Inhibition of aldose reductase prevents angiogenesis in vitro and in vivo. Angiogenesis 2011; 14: 209-21.

26. Tammali R, Reddy ABM, Saxena A, et al. Inhibition of aldose reductase prevents colon cancer metastasis. Carcinogenesis 2011; 32: 1259-67.

27. Shoeb M, Ramana KV, Srivastava SK. Aldose reductase inhibition enhances TRAIL-induced human colon cancer cell apoptosis through AKT/FOXO3a-dependent upregulation of death receptors. Free Radic Biol Med 2013; 63: 280-90.

28. Ramana KV, Tammali R, Srivastava SK. Inhibition of aldose reductase prevents growth factor-induced G1-S phase transition through the AKT/phosphoinositide 3-kinase/E2F-1 pathway in human colon cancer cells. Mol Cancer Ther 2010; 9: 813-24.

29. Subhani S, Jayaraman A, Jamil K. Homology modelling and molecular docking of MDR1 with chemotherapeutic agents in non-small cell lung cancer. Biomed Pharmacother 2015; 71: 37-45.

30. Türe A, Kahraman DC, Cetin-Atalay R, Helvacıoğlu S, Charehsaz M, Küçükgüzel İ. Synthesis, anticancer activity, toxicity evaluation and molecular docking studies of novel phenylaminopyrimidine-(thio)urea hybrids as potential kinase inhibitors. Comput Biol Chem 2019; 78: $227-41$. 